\author{
УДК 371.7 \\ https://doi.org/10.36906/FKS-2021/106
}

Фuxmep O.B.

Средняя школа № 23,

г. Нижневартовск, Россия

\title{
К ВОПРОСУ ОБ ЭФФЕКТИВНОСТИ ОРГАНИЗАЦИИ ФИЗКУЛЬТУРНО- ОЗДОРОВИТЕЛЬНОЙ И СПОРТИВНОЙ ДЕЯТЕЛЬНОСТИ В ШКОЛЕ
}

Аннотация. Современное состояние системы школьного образования требует пристального внимания к содержанию и организации физкультурно-оздоровительной и спортивной деятельности в условиях образовательного учреждения. Классическая система физического воспитания нуждается в расширении границ физкультурнооздоровительной и спортивной работы с целью обеспечения необходимого уровня физического состояния обучающихся в школе.

Ключевые слова: физическое воспитание, физкультурно-оздоровительная работа, спортивная деятельность, школьники.

Fikhter $\boldsymbol{O} . \boldsymbol{V}$.

Secondary school № 23,

Nizhnevartovsk, Russia

\section{TO THE QUESTION OF THE EFFICIENCY OF THE ORGANIZATION OF HEALTHY HEALTH AND SPORTS ACTIVITIES AT SCHOOL}

Annotation. The current state of the school education system requires close attention to the content and organization of physical culture, health and sports activities in an educational institution. The classical system of physical education needs to expand the boundaries of physical culture and health and sports work in order to ensure the required level of physical condition of students at school.

Keywords: physical education, physical culture and health improvement work, sports activity, schoolchildren.

В современном мире все больше осознают необходимость роли физической культуры и спорта, как фактора совершенствования человека и общества. Общеизвестно, что вовлеченность большинства населения в массовое физкультурно-спортивное движение, а также успешные выступления спортсменов на международных аренах являются бесспорным доказательством жизнеспособности и духовной силы нации. В России физическая культура и спорт стали, предметом национальной гордости, сплоченности и национальной идеей, способствующей дальнейшему развитию государства и здорового общества [8, с. 240; 9 , c. 54].

Физическому воспитанию детей и подростков в общеобразовательной школе сейчас уделяется большое внимание. Это необходимо для повышения эффективности решения задач формирования здорового образа жизни детей и подростков, увеличения двигательного потенциала школьников, становления необходимых жизненно важных умений и навыков [4, c. $354 ; 5$, с. 107$]$.

В условиях современной российской школы физического воспитания большое значение придается двигательному режиму обучающихся в школе. От его грамотной 
организации во многом зависят уровень здоровья и работоспособности детей и подростков. Рациональный двигательный режим обучающихся должен включать различные виды физкультурно-оздоровительной и спортивной деятельности в школе. Системное чередование их с уроками обеспечивает значительный уровень двигательной активности, снижает утомление обучающихся и повышает эффективность учебной работы [2, с. 97; 7, с. 187].

Например, на сегодняшний день накоплен опыт внедрения спортизированных форм занятий, которые позволяют не только существенно повысить уровень физической подготовленности школьников, но и главным образом поменять отношение обучающихся к двигательной активности [1, с. 15; 6, с. 72].

При всей значимости урока как основы процесса физического воспитания в школе главенствующую роль в приобщении к ежедневным занятиям физическими упражнениями обучающихся принадлежит физкультурно-оздоровительной и спортивно-массовой работе.

Уроки физической культуры лишь частично пополняют недостаток движений и, если обучающиеся дополнительно не будут заниматься физической культурой и спортом, это может повлечь за собой приостановку в развитии его моторики.

В последние годы эта работа наряду со сложившимися ее формами практически обогатилась весьма эффективными видами оздоровления обучающихся, повышения их работоспособности, в определенной степени психологического воздействия на их сознание о необходимости использования физической культуры и спорта в своей повседневной деятельности. Физкультурно-оздоровительные мероприятия, как правило, должны охватывать всех обучающихся каждой школы.

Цель спортивно-массовых и физкультурно-оздоровительных мероприятий пропаганда физической культуры и спорта, приобщение школьников к систематическим занятиям физическими упражнениями и различными видами спорта, подведение итогов физкультурно-спортивной работы, активный отдых, сохранение и укрепление здоровья обучающихся, воспитание потребности и умения самостоятельно заниматься физической культурой, формирование навыков и развитие мотивации обучающихся к выбору здорового образа жизни.

Рассматривая педагогические аспекты организации двигательного режима, следует в первую очередь иметь в виду содержание и методику проведения его элементов. В ряде исследовании отмечается роль правильной организации двигательного режима и насыщения его различными формами физкультурных занятий для формирования у школьников потребности в занятиях физическими упражнениями. Подчеркивается важность умелого проведения гимнастики до занятий, физкультурных минут, игр на перемене для повышения активности обучающихся и их интереса к физическому воспитанию [3, с. 63].

Комплексное использование всех видов и форм физкультурно-оздоровительной деятельности обеспечивает эффективность оптимального режима при условии применения рациональных современных технологий. Систематическое проведение физкультурнооздоровительной работы в режиме учебного и продленного дня оказывает благоприятное воздействие на динамику умственной работоспособности обучающихся в течение учебного года. При этом, у обучающихся значительно повышается двигательная активность, повышается уровень физической работоспособности и двигательной подготовленности.

Рассматриваемые в статье вопросы организации внеурочной деятельности и внеклассной физкультурно-оздоровительной и спортивно-массовой работы в школе свидетельствуют о многосторонности форм и методов данной работы. Постоянно проводимая работа требует значительного труда всего педагогического коллектива школы, в особенности 
учителей физической культуры, ка начинающих свой путь в профессии, так и педагоговноваторов.

Поэтому, важнейшим направлением в проведении многообразных физкультурноспортивных и оздоровительных мероприятий должно быть активное и заинтересованное участие, прежде всего самих школьников различного возраста. Организация физкультурнооздоровительных мероприятий не должна быть стихийной, а точно продуманной работой всего слаженного творческого коллектива общеобразовательной школы. Ее следует регулярно координировать администрацией, учителями физического воспитания, педагогами-организаторами. В системную работу должен включиться весь педагогический арсенал сотрудников школы. Такие мероприятия должны стать еще более плодотворными и эффективными, если она будет тесно взаимосвязана и подкреплена внешкольными формами физического воспитания самих обучающихся.

Основным принципом, обусловливающим специфику занятий с обучающимися во внеурочное время, является свобода в выборе форм и направлений данных занятий. Важно, чтобы обучающимся был предоставлен выбор кружков или спортивных секций.

Поскольку весьма острой проблемой является укрепление и сохранение здоровья детей, то на первый план в свободный от учёбы день выходит организация физкультурноспортивной и оздоровительной деятельности, имеющей целью формирование ценностного отношения к собственному здоровью, физической культуре и спорту, здоровому образу и стилю жизни.

Осуществление комплексного подхода к воспитанию требует, чтобы при организации всех мероприятий решалась бы не только одна профильная задача, важно, чтобы каждое мероприятие решало максимум воспитательных задач. При выборе содержания, форм организаций всегда необходимо соблюдать принцип учёта возрастных и индивидуальных особенностей обучающихся. Важным условием действенности всех видов воспитательной работы является обеспечение их единства, преемственности и взаимодействия.

В результате проведенного анкетирования учителей физической культуры, работающих в г. Нижневартовске, было выявлено, что из опрошенных нами учителей: 91\% имеют высшее образование, 11\% имеют среднее специальное образование. Трудовой стаж учителей физической культуры в общеобразовательной школе составил: $2 \%$ менее трех лет, $33 \%$ до десяти лет, $65 \%$ опрошенных педагогов имеют стаж педагогической деятельности более двадцати лет. На вопросы: «Участвуете ли Вы в разработке спортивно-массовых мероприятий?» положительно ответили 100\% опрошенных учителей.

Все учителя физической культуры регулярно принимают участие в судействе спортивных соревнований, а также в проведении физкультурно-оздоровительных и спортивных мероприятий школы. На вопрос «Существует ли возможность проведения спортивно-массовых мероприятий вне территории школы (туристические базы, бассейны и т. д.?) «да» ответили - 84\%, «нет» ответили $-16 \%$.

Таким образом, необходим дальнейший поиск эффективных способов организации физкультурно-оздоровительной и спортивной деятельности в школе, которые привнесут новизну и повысят интерес обучающихся в школе детей и подростков.

\section{Литература}

1. Бальсевич В.К. Спортивный вектор физического воспитания в российской школе. М.: Теория и практика физической культуры и спорта, 2006. 112 с.

2. Давыдова С.А., Пащенко Л.Г., Синявский Н.И., Фурсов А.В. Автоматизированная система текущего контроля и управления физической подготовленностью обучающихся на 
основе требований комплекса ГТО // Теория и практика физической культуры. 2019. № 8. C. $96-98$.

3. Крылова Т.И. Образ жизни для сохранения и укрепления здоровья // Физическая культура в системе профессионального образования: идеи, технологии и перспективы: сборник материалов VI Всероссийской научно-практической конференции. Омск: Изд-во ФГБОУ ВО Омский ГАУ, 2021. С. 60-64.

4. Курамшин Ю.Ф. Проблемы модернизации физического воспитания учащейся молодежи // Здоровье - основа человеческого потенциала - проблемы и пути их решения. СПб.: Изд-во: СПбГПУ, 2011. Т. 6. № 1. С. 353-354.

5. Лубышева Л.И. Спортизация в общеобразовательной школе. М.: Теория и практика физической культуры, 2009. 168 с.

6. Пащенко Л.Г., Красникова О.С. Анализ применяемых учителями физической культуры современных образовательных технологий // Культура, наука, образование: проблемы и перспективы: материалы IV Всероссийской научно-практической конференции, Нижневартовск, 12-13 февраля 2015 года. Нижневартовск: Нижневартовский государственный университет, 2015. С. 186-188.

7. Пащенко Л.Г., Красникова О.С., Коричко Ю.В. Отношение родителей школьников к семейному физическому воспитанию // Физическая культура: воспитание, образование, тренировка. 2014. № 3. С. 71-76.

8. Пащенко Л.Г., Красникова О.С., Коричко Ю.В., Полушкина Л.Н.Использование современных педагогических технологий учителями физической культуры в профессиональной деятельности//Актуальные проблемы гуманитарных и естественных наук. 2014. № 3-2. С. 238-241.

9. Фонарев Д.В. Использование инновационной технологии спортивно ориентированного физического воспитания в средних общеобразовательных учреждениях. Чайковский: ЧГИФК, 2003. 71 с.

10. Фурсов А.В., Синявский Н.И. Педагогический контроль физической подготовленности обучающихся на основе применения онлайн-сервиса «АС ФСК ГТО» // Физическая культура в школе. 2020. № 2. С. 16-21.

(C) Фuxmep O.B., 2021 